\title{
Catch fast and kill quickly: do tiger beetles use the same strategies when hunting different types of prey?
}

\author{
Tomasz Rewicz ${ }^{1}$, Radomir Jaskuła ${ }^{\text {Corresp. } 1}$ \\ ${ }^{1}$ Department of Invertebrate Zoology and Hydrobiology / Faculty of Biology and Environmental Protection, University of Lodz, Łódź, Poland \\ Corresponding Author: Radomir Jaskuła \\ Email address: radomir.jaskula@biol.uni.lodz.pl
}

Background. Tiger beetles (Coleoptera: Cicindelidae) are fast running predatory insects preying on different small insects and other terrestrial arthropods. Prey is located by sight and captured after short and fast pursuit interspersed with pause-and- look behaviour. At least some tiger beetle species can recognise the size and location of prey using memory, which probably allows them to achieve greater hunting success.

Material and methods. Two eurytopic tiger beetle species known to occur in different types of habitat were used in the study: Cicindela hybrida hybrida, a very common central European beetle found even in artificial habitats such as sandy roads or gravel pits, and Calomera littoralis nemoralis, a species widely distributed in southern European countries and occurring on sandy sea beaches, in salt marshes, as well as on sandy banks of rivers and lakes. Both species are very similar in body size. Specimens used in the study were collected in the field and later tested in the laboratory. We checked whether tiger beetles use different hunting strategies when attacking prey of different sizes and abilities to escape as well as whether the sex of the studied species makes a difference in its hunting behaviour.

Results. The hunting strategies of both tiger beetle species consist of the following main phases: identification, pursuit (often with stops), attack, and optional release of the prey, and then the secondary attack, abandonment of the prey, or consumption of the prey. Considerable differences were noticed in hunting behaviour depending on the type of prey, its movement ability and escape potential. Caterpillars were attacked without pursuit, in the head or directly behind the head where a concentration of nerves and main muscles responsible for walking are located. Effective attacks on beetles were executed at the connection between the thorax and the abdomen. Calomera littoralis strongly preferred slow moving prey, while Cicindela hybrida preferred in equal measure slow moving prey and medium-sized fast moving prey. The experiment on the preferred size of prey indicated small beetles and small caterpillars as favoured by Calomera littoralis, while Cicindela hybrida preferred medium-sized fast moving prey and large caterpillars.

Discussion. The hunting behaviour of Calomera littoralis and Cicindela hybrida is complicated and includes a number of phases allowing to locate, capture and kill the prey. Beetles are able to discriminate between different types of prey and apply different behavioural tactics to hunt it. As the particular strategies are used to increase hunting success, and as a result allow to accumulate energy for future activity of the predator, it can be expected that such a type of hunting behaviour is characteristic also of other tiger beetle species. 
1 Catch fast and kill quickly: do tiger beetles use the same strategies when hunting different 2 types of prey?

3

4 Tomasz Rewicz ${ }^{1}$, Radomir Jaskuła ${ }^{2}$

$5 \quad{ }^{1}$ Department of Invertebrate Zoology and Hydrobiology, University of Lodz, 12/16 Banacha, 90-

$6237 \mathrm{Lodz}$, Poland

$7{ }^{2}$ Department of Invertebrate Zoology and Hydrobiology, University of Lodz, 12/16 Banacha, 90-

8237 Lodz, Poland

9

10

11 Corresponding author:

12 Radomir Jaskuła

13 Department of Invertebrate Zoology and Hydrobiology, University of Lodz, 12/16 Banacha, 14 Lodz 90-237, Poland, e-mail: radomir.jaskula@biol.uni.lodz.pl 


\section{Abstract}

Background. Tiger beetles (Coleoptera: Cicindelidae) are fast running predatory insects preying on different small insects and other terrestrial arthropods. Prey is located by sight and captured after short and fast pursuit interspersed with pause-and- look behaviour. At least some tiger beetle species can recognise the size and location of prey using memory, which probably allows them to achieve greater hunting success.

Material and methods. Two eurytopic tiger beetle species known to occur in different types of habitat were used in the study: Cicindela hybrida hybrida, a very common central European beetle found even in artificial habitats such as sandy roads or gravel pits, and Calomera littoralis nemoralis, a species widely distributed in southern European countries and occurring on sandy sea beaches, in salt marshes, as well as on sandy banks of rivers and lakes. Both species are very similar in body size. Specimens used in the study were collected in the field and later tested in the laboratory. We checked whether tiger beetles use different hunting strategies when attacking prey of different sizes and abilities to escape as well as whether the sex of the studied species makes a difference in its hunting behaviour.

Results. The hunting strategies of both tiger beetle species consist of the following main phases: identification, pursuit (often with stops), attack, and optional release of the prey, and then the secondary attack, abandonment of the prey, or consumption of the prey. Considerable differences were noticed in hunting behaviour depending on the type of prey, its movement ability and escape potential. Caterpillars were attacked without pursuit, in the head or directly behind the head where a concentration of nerves and main muscles responsible for walking are located. Effective attacks on beetles were executed at the connection between the thorax and the abdomen. Calomera littoralis strongly preferred slow moving prey, while Cicindela hybrida preferred in equal measure slow moving prey and medium-sized fast moving prey. The experiment on the preferred size of prey indicated small beetles and small caterpillars as favoured by Calomera littoralis, while Cicindela hybrida preferred medium-sized fast moving prey and large caterpillars.

Discussion. The hunting behaviour of Calomera littoralis and Cicindela hybrida is complicated and includes a number of phases allowing to locate, capture and kill the prey. Beetles are able to discriminate between different types of prey and apply different behavioural tactics to hunt it. As the particular strategies are used to increase hunting success, and as a result allow to accumulate 
47 energy for future activity of the predator, it can be expected that such a type of hunting behaviour 48 is characteristic also of other tiger beetle species.

49 


\section{Introduction}

52

Tiger beetles (Coleoptera: Cicindelidae) are small to medium-sized predatory beetles hunting for a variety of small, mostly typically epigeic invertebrates. Most species of these fast running predators are characterised by diurnal activity (Pearson \& Vogler, 2001). Although they typically use sight to locate their fast moving prey (Świecimski, 1956; Gilbert, 1987; Gilbert 1997), sometimes even day active species can capture prey in complete darkness, which suggests that other senses, such as chemoreception, audioreception and mechanoreception, may play an important role in searching for prey in this beetle group (Riggins \& Hoback, 2005). A large spectrum of prey, including e.g.: Coleoptera, Hymenoptera, Orthoptera, larvae of Lepidoptera, but also spiders or small crustaceans, indicates that these beetles are opportunistic hunters (Larochelle, 1974; Pearson, 1988; Pearon \& Vogler, 2001). They may also consume plant material as food (Hori, 1982; Hill \& Knisley, 1992; Jaskuła, 2013). Although the diet of tiger beetles as a group is rather well known, little is known about prey preferences and/or hunting strategies of most species. Generally, a tiger beetle locates its live prey visually and after that starts to pursue it in the course of active running interspersed with pause-and-look behaviour (Gilbert, 1987; Gilbert, 1997) or the beetle waits in a shaded area and attacks the prey when it is approaching (Kaulbars \& Freitag, 1993). Pearson and Knisley (1985) have observed that if the attack is successful, the beetle grabs the prey with its mandibles. Before the prey is consumed, the beetle starts to test it in terms of size, hardness, and noxious chemicals. When the prey is too large and/or is inedible because of some chemical substances, it is quickly released. Moreover, Świecimski (1956) has noted that tiger beetles use memory of the shape and location of prey to distinguish small prey located at a shorter distance from large prey placed at a greater distance. Flexibility in terms of hunting strategies usually brings a significant benefit to the predator. Predatory species which use different behavioural tactics can feed on a larger variety of food, and as a consequence, they can survive in habitats with a low number of specific prey (= higher adaptation rates to environmental change) and/or colonise new areas (= higher dispersal ability). Moreover, individuals of such opportunistic species can more easily and more rapidly accumulate energy needed during the reproduction process, which is especially important for females (Curio, 1976). 
80 The aims of this study were: $1 /$ to verify if tiger beetles prefer particular type and size of prey, 81 with different ability to escape, 2/ to determinate if tiger beetles use different hunting strategies when attacking prey of different sizes and abilities to escape, 3 / to verify if sex of the studied species makes a difference in its hunting behaviour. Since in most Cicindelidae females are larger it is expected that females would prefer to hunt for larger prey than males.

\section{Material and methods}

\section{Predator}

To test our hypotheses, we have chosen two tiger beetle species. Calomera littoralis nemoralis (Olivier, 1790), one of the most common Cicindelidae species in the Mediterranean region, having one of the widest habitat ranges among all tiger beetles known from this region (Wiesner, 1992; Jaskuła, 2011; Jaskuła, 2015; Jaskuła \& Rewicz, 2015; Jaskuła et al., 2015, Jaskuła et al., 2016). Specimens were collected in the mouth of the Evros River (4049'9.29"N, 2559'28.59"E) on the Greek marine sandy beach. Cicindela hybrida hybrida Linnaeus, 1758, the most common tiger beetle species known from Central Europe, also recognised as an eurytopic species according to habitat types (Wiesner, 1992; Jaskuła 2003). Specimens were collected in Krzywie $\left(51^{\circ} 51^{\prime} 26.49^{\prime \prime} \mathrm{N}, 19^{\circ} 26^{\prime} 48.18^{\prime \prime} \mathrm{E}\right)$ in an old gravel pit in Central Poland. Adult beetles from both species were collected with an entomological net in August 2008.

A few dozen males and females from both species were caught and taken to the laboratory.

Specimens were kept separately in transparent plastic containers with 2-cm layer of sand at the bottom. The proper humidity was maintained through regular water spraying. The experiment was carried at the stable temperature of $24^{\circ} \mathrm{C}$ and in the natural photoperiod. Beetles were fed daily by ants (Lasius niger) during the whole week before experiment 1 .

\section{Prey}

Based on earlier personal observations in the field, six taxa of common prey of tiger beetles were chosen for the study. These were: larvae of grasshoppers (Orthoptera: Acrididae), Bembidion lampros/B. properans, Calathus melanocephalus, C. fuscipes (Coleoptera: Carabidae), and larvae of Symphyta (Hymenoptera). Bembidion lampros and B. properans were considered as one type of prey due to their similar weight and size and because of difficulties in correct identification of species when the beetle is alive and fast moving. Caterpillars of Symphyta correspond to the next three stages of their development (Table 1). As different types of prey 
111 possess different abilities to escape, we have divided them into three groups: 1/ Orthoptera -

112 possess a high escape potential as they have jumping legs and can jump a long distance away; 2/

113 ground beetles (Carabidae) - have a medium escape potential as they can run fast and dodge, or

114 turn over, additionally they have the ability to exude a chemical weapon in emergency situations;

1153 / caterpillars - are unable to move quickly or dodge and turn over so they are characterised by a

116 small escape potential (Tab 1). Caterpillars and grasshopper larvae were collected in the field by

117 entomological net, and carabids by exhauster. Different types of prey were collected on a day

118 before the experiment, and stored individually in a refrigerator in order to reduce their mortality.

119 Experimental procedure

120 We conducted experiments in 20-cm diameter plastic buckets with a 2-cm layer of sand at the

121 bottom. Each individual was kept separately. All experiments were conducted between 10:00 and

122 14:00 hours under natural light, during the highest hunting activity of tiger beetles. The

123 experiment 1 started after 1 day of hunger. The next experiments were carried out in specific

124 order: finish of experiment 1 , feeding in next day, one day of hunger, day with experiment 2 ,

125 feeding in next day, one day of hunger and experiment 3.

126 In each experiment, each specimen was used only once.

127 Types of experiment

\section{Prey escape potential}

129 Each tiger beetle (both species, both sexes) got three different types of prey dropped into the 130 experimental bucket at the same time. Preferences of the prey type were recorded after the prey 131 was caught and eaten. Feeding happened in the mornings (10:00) or at noon (12:00), and after 132 two hours the buckets were examined to check which prey was caught and eaten. The types of 133 prey represent different escape potentials: low - medium caterpillar of Symphyta, medium -

134 Calathus melanocephalus, high - grasshopper. The number of repetitions differs between species 135 and/or sexes (Table 2) because a different number of species and sexes were collected, and if a 136 tiger beetle specimen refused to attack the prey three times (three periods of two hours' feeding), 137 it was eliminated from this experiment.

138 Prey size

139 Experiment 2 consisted of two parts ( $\mathrm{a}$ and $\mathrm{b}$ ). Each specimen (both species, both sexes) got 140 three carabid beetles (part a) or three caterpillars (part b) of different size (Table 2) dropped into 141 the experimental bucket at the same time. In both cases preferences of the prey size were noticed 
142 after the prey was caught and eaten, while feeding and checking were conducted under same

143 conditions as in Experiment 1. Particular, random number of prey individuals measured are 144 presented in Table 1.

\section{Hunting strategies}

146 In Experiment 3, we checked if tiger beetles use different hunting strategies for different prey 147 types. Specimens (both species, both sexes) were observed separately and every step of their 148 hunting behaviour was noted on special work cards. On the cards, we included each major step 149 of hunting sequences. Types and sizes of prey that were used in this step of the experiment were 150 a result of the two previous experiments and included the most preferred choices of each species 151 and sex of tiger beetle (Table 2).

\section{Data analysis}

153 In Experiment 1 and 2, we counted the number of repetitions and drew diagrams of preferences 154 in terms of type and size of prey. We interpreted number of repetitions as attack for one from 155 three provided preys in experiment 1 and 2 (one of three types of preys in experiment 1 and 156 experiment 2 respectively). Moreover, in experiment 2 correlation between predator body size and prey body size was measured. In Experiment 3 each step of the hunting strategy was checked for significant differences between the species and sexes. The frequency of particular steps was calculated as a percentage of such behaviour in relation to all possible behaviours between two successive stages of hunting, and was indicated by the width of the line in the diagram and by the number above the line. The sequence of the hunting strategy was analysed and the frequency of key steps in each species and strategy was calculated. Preferences regarding the type and size of prey for both sexes and species of tiger beetles as well as key steps of the hunting sequence were analysed using Pearson's chi-squared test.

\section{Results}

\section{Prey escape potential}

168 Calomera littoralis males and females chose most often caterpillars ( $91 \%$ to $98 \%$ respectively), then ground beetles ( $8 \%$ to $2 \%$ ), and almost ignored grasshoppers (1\% to $0 \%)$ (Fig.1). Cicindela hybrida males and females chose caterpillars (49\% to 44\%), almost the same often as ground

171 beetles (51\% to $52 \%)$ and least willingly caterpillars (0\% to $4 \%)$ (Fig. 1). There is no dominant 172 type of prey for males and females of $C$. hybrida $(\chi 2=0.260, \mathrm{df}=1, \mathrm{p}=0.05)$. However, both 
173 sexes completely ignored grasshoppers as the prey and selecting beetles and caterpillars with

174 practically equal frequency. Preferences of the prey type between C. hybrida and Calomera

175 littoralis differ significantly $\left(\chi^{2}=65.18, d f=1, \mathrm{p}=0.05\right)$.

176 Prey size

177 Size preferences - carabid beetles

178 C. littoralis males and females chose a small beetle (91\% to $100 \%)$, and less often medium

179 beetle ( $9 \%$ to $0 \%$ ). Cicindela hybrida males and females chose small beetles (30\% to $57 \%$ ), then

180 medium beetle ( $66 \%$ to $43 \%$ ) and least willingly large beetles ( $4 \%$ to $0 \%$ ) (Fig. $2 \mathrm{~A})$. The size of

181 the preferred beetle prey was significant between the sexes of $C$. hybrida $\left(\chi^{2}=6.830, d f=1\right.$,

$182 \mathrm{p}=0.05)$. Preferences of the beetle prey size between C. hybrida and Calomera littoralis differ

183 significantly $\left(\chi^{2}=54.522, d f=1, \mathrm{p}=0.05\right)$.

184 Size preferences - caterpillars

185 C. littoralis males and females chose small caterpillars (51\% to 52\%), medium caterpillars (27\%

186 to $25 \%)$ and large ones (22\% to $23 \%$ ) (Fig. 2B). There were no significant differences between

187 the sexes of $C$. littoralis and the preferred caterpillar size $\left(\chi^{2}=0.047, d f=2, \mathrm{p}=0.05\right)$. Cicindela

188 hybrida males and females chose small caterpillars (22\% to $19 \%$ ), medium ones ( $31 \%$ to $34 \%$ ),

189 and large ones (47\% to 47\%). There were no significant differences between the sexes of $C$.

190 hybrida and the preferred caterpillar size $\left(\chi^{2}=0.243, d f=2, \mathrm{p}=0.05\right)$. Preferences of the caterpillar

191 prey size between $C$. hybrida and Calomera littoralis differ significantly $\left(\chi^{2}=25.062, d f=1\right.$,

$192 \mathrm{p}=0.05)$.

193 Predator-prey body-size ratiosMales of both studies tiger beetles species were characterized by

194 constant value of prey length in relation to length of predator where both beetles and caterpillars were

195 used as prey. In contrast, in case of females constant value of prey body-size was noted only in case of $C$.

196 littoralis hunting on beetles. In females of the some species hunting on caterpillars positive correlation

197 between predator and prey body-size was found while in females of Cicindela hybrida negative

198 correlation was noted for both types of studied preys (Fig. 3).

199 Hunting strategies

200 We tested if there were differences between sexes of each species in each major step of the

201 hunting scenario. In most cases, we found there were no differences between the sexes, and we

202 decided to simplify the results of Experiment 3 and to summarise repetitions of both sexes of

203 each species.

204 Scenario of hunting prey with different escape potentials 
205 Regardless of the type of prey, the first steps of the hunting pattern were the perception of the 206 prey, followed by the turning of the hunter toward the prey. Next the tiger beetle freezes for a

207

208

209

210

211

212

213

214

215

216

217

218

219

220

221

222

223

224

225

226

227

228

229

230

231

232

233

234

235

moment (stops), and starts to chase the prey fast in the case of beetles, or nobble the prey slowly in the case of slow caterpillars. The mandible attacks were conducted against three parts of the prey body: front, middle and back. In the case of beetle and caterpillar prey that meant: the front part - head, or the initial sections of the thorax; the middle part the narrow part between the pronotum and the abdomen - the final sections of the thorax or the initial sections of the abdomen; the back part - the abdomen (respectively). We can observe that both species preferred to attack caterpillars in the front or middle part of the body, and avoid the back part. Tiger beetles preferred attacking in its middle part or - less often - the back part, when hunting for fast moving prey. We noticed only one attack on the front part of a beetle (Fig. 4C). After the attack (stabbing with the mandibles), the hunters followed two scenarios; either the attack was lethal and immediately after they ate the prey, or the prey managed to escape after the first stab. After releasing the prey, the hunters mostly retried the attack (re-attack), even repeatedly to achieve the lethal effect. Less often the hunters abandoned (abandonment of the prey) the dead prey, or finished the attack by leaving the wounded prey (ineffective attack). Sometimes after eating the prey only partially, or after an ineffective attack, they would abandon the prey and start digging the ground with mandibles.

\section{Behavioural prey-type specificity}

The beginning of the hunting strategy of Cicindela hybrida towards beetles and caterpillars looks similar - after visual prey perception, the hunter turns toward the prey and after a moment of observation chases and stabs the prey. The main difference between the strategies concerns the site of the attack. Almost all attacks towards beetles (96\%) were conducted in the middle part of their body, in the case of caterpillars the back part was less preferable (9\%), most favourable were the front part $(50 \%)$ and the middle part $(35 \%)\left(\chi^{2}=55.18, d f=2, \mathrm{p}<.001\right)$. (Fig. 4B \& D). After the first attack, the prey was released and attacked again. Caterpillars were abandoned more often than beetles ( $12 \%$ to $3 \%$ respectively) $\left(\chi^{2}=4.63, d f=1, \mathrm{p}<.05\right)$. The last stage of the hunting strategy was also different, $C$. hybrida searched the area more often after hunting caterpillars $(37 \%$ to $17 \%)\left(\chi^{2}=7.14, d f=1, \mathrm{p}<.05\right)$.

The hunting strategy of Calomera littoralis against beetles and caterpillars shows more differences than similarities (Fig. 4A \& C). The first clear difference is a lack of chase stage in 
236 the case of caterpillars ( $11 \%$ to $88 \%$ when attacking beetles) $\left(\chi^{2}=91.62, d f=1, \mathrm{p}<.05\right)$. The

237 attack against beetles was conducted in $76 \%$ in the middle part of the body, and against

238 caterpillars in the front part (39\%) and the middle part (57\%), which was a significant difference

239 between those types of prey $\left(\chi^{2}=38.95, d f=2, \mathrm{p}<.00001\right)$. After the first attack, we can observe

240 quite a high level of killed and eaten prey (42\% for beetles and 57\% for caterpillars), but still

241 there was no significant difference between types of prey. However, killed caterpillars were

242 abandoned more often than beetles ( $17 \%$ to $3 \%$ respectively) $\left(\chi^{2}=8.95, d f=1, \mathrm{p}<.05\right)$.

243 Altogether it indicates the predator's greater efficiency when hunting beetles (91\% killed and

244 eaten prey, compared to 70\% killed and eaten caterpillars). C. littoralis searches the area more

245 often after hunting beetles than caterpillars $(46 \%$ to $26 \%)\left(\chi^{2}=6.41, d f=1, \mathrm{p}<.05\right)$.

\section{Behavioural hunter-species specificity}

247 The hunting pattern for beetles was quite simple for both hunter species. The main attack sequence was straightforward: prey perception, turn, stop, chase, attack on the middle part of the body, releasing the prey, re-attack, eating the prey. Deviations from this pattern were not abundant. We can observe that tiger beetles clearly prefer attacking the middle part of the prey

251

252

253

254

255

256

257

258

259

260

261

262

263

264

265

266 (Calomera littoralis 76\%, Cicindela hybrida 96\%) (Fig. 4C \& D), and almost ignore the front and back parts. The difference between tiger beetle species appears after the attack, $C$. littoralis in $58 \%$ of cases released the prey after the first stab ( $\mathrm{n}=44)$, and C. hybrida in $78 \%$ of cases $(\mathrm{n}=59)\left(\chi^{2}=6.78, d f=1, \mathrm{p}<.05\right)$. As a consequence, also the re-attack occurred more often in C. hybrida than in Calomera littoralis ( $75 \% \mathrm{n}=57$ to $51 \% \mathrm{n}=39$ respectively). C. littoralis kills faster than Cicindela hybrida, we can observe $42 \%$ of killed beetles after the first attack, and only $22 \%$ in the case of $C$. hybrida $\left(\chi^{2}=6.78, d f=1, \mathrm{p}<.01\right)$. However, effectiveness of hunting beetles between Calomera littoralis and Cicindela hybrida was almost identical with $91 \% n=69$ and $89 \% n=89$ of respectively killed and eaten prey. One more curious behaviour occurred much more often in the Calomera littoralis pattern. This species searched the area after hunting in $42 \%$ of cases, which is significantly different than $14 \%$ of such behaviour instances in Cicindela hybrida $\left(\chi^{2}=14.74, d f=1, \mathrm{p}<.001\right)$.

The hunting strategies towards caterpillars were more complicated than towards beetles. We can observe the first difference between hunter species in chasing or approaching the prey after turning towards it. $C$. hybrida uses the same pattern as towards beetles - it freezes for a moment and then chases the prey $(94 \%, \mathrm{n}=64)($ Fig 4B). Surprisingly, Calomera littoralis after freezing 
267 approaches slowly $\left(11 \%, \mathrm{n}=8\right.$, fast chase) the prey before stabbing $\left(\chi^{2}=100.31, d f=1, \mathrm{p}<\right.$

268 .001). Both hunters stab the caterpillar mostly in the head or the middle part of the body, less

269 than $10 \%$ of attacks were carried to the back part. After the first attack, $C$. littoralis released the 270 prey in $43 \%$ of cases $(n=33)$, and Cicindela hybrida significantly more often $(76 \%, n=52)\left(\chi^{2}=\right.$

$27116.21, d f=1, \mathrm{p}<.001)$. In consequence, the re-attack occurred only in $24 \%$ of cases for

272 Calomera littoralis and in $66 \%$ of cases for Cicindela hybrida $\left(\chi^{2}=26.33, d f=1, \mathrm{p}<.05\right)$.

273 Calomera littoralis has a higher level of success of the first attack and kill, as it happened in 57\%

274 of cases and only in $24 \%$ of cases the first stabbing by Cicindela hybrida resulted in a killed and

275 eaten caterpillar $\left(\chi^{2}=16.21, d f=1, \mathrm{p}<.001\right)$. However, overall hunting effectiveness was

276 similar, and both hunting species killed and ate more than $70 \%$ of their prey.

\section{Discussion}

278 Although both tiger beetle species used in the experiments can be characterized by similar body

279 size and are known as predators hunting different small arthropods (mainly epigeic insects),

280 occasionally eating also dead insects (Cicindela hybrida - Świecimski, 1956) or even plant

281 material (Calomera litoralis - Jaskuła, 2013), the beetles differ in case of other ecological

282 aspects, including geographical distribution and habitat preferences (Driesig, 1981; Wiesner,

283 1992; Jaskuła, 2011). That makes both species opportunistic predators hunting for the type of

284 prey which is actually available in the beetle's habitat as it was shown in some other tiger beetle

285

286 species occurring in different parts of the world (e.g. Sinu et al., 2006). Moreover, it also may predict significant differences in their hunting strategies and prey references (Brose et al., 2006). Our results clearly confirm the ability of Cicindela hybrida and Calomera littoralis to catch and kill different types of prey in terms of body size and mobility. On the other hand, we have noted that in the case of prey mobility, a large number of $C$. littoralis (91 or $98 \%$ depending on the beetle sex) and almost half of the studied specimens of Cicindela hybrida (44 or 49\% depending on the beetle sex) preferred caterpillars which cannot escape faster than fast running beetles. Such a strategy can be clearly explained when the energetic cost of such a predatory behaviour is analysed (Brose et al., 2008). From the predator's point of view, predation is a very energyconsuming activity as prey needs to be located, which often takes time, caught and killed, which requires additional energy for a potential fight with the prey, and is often dangerous also for the predator as it can be injured. And if the attack is not successful, the predator needs to look for another prey and repeat all the parts of such a behaviour again and again (Bonsall \& Hassell, 
298

299

300

301

302

303

304

305

306

307

308

309

310

311

312

313

314

315

316

317

318

319

320

321

322

323

324

325

326

327

328

2007; Creel \& Christianson, 2008). Taking this into consideration, hunting for slow moving prey characterised by a small escape potential is much better as it allows the predator to preserve more energy for any future activity. On the other hand, in the case of $C$. hybrida, fast moving beetles were noted as very important prey, too (51 or $52 \%$ depending on the beetle sex). This confirms earlier observations by Świecimski (1956), who noted that this species chooses fast moving prey as their faster movement can be probably easier perceived by the predator. On the other hand, ignoring this type of prey by Calomera littoralis (if slow moving caterpillars were available as food) can be probably explained by chemical defence regularly used by different ground beetle species, including Calathus and Bembidion beetles (Moore, 1979), as it is known that tiger beetles often release prey which emits chemicals (Pearson \& Knisley, 1985). In the case of habitats where Cicindela hybrida occurs, both Calathus melanocephalus and Bembidion lampros/properans are regularly observed, and the tiger beetle was observed hunting for them (Jaskuła - personal observations), while in the case of habitats occupied by Calomera littoralis, these species of ground beetles are rarely encountered or even do not occur at all. As a consequence, we cannot exclude the assumption that a lack of potential contact between the prey and the predator under natural conditions does not play a role in choosing the prey under laboratory conditions. As experiments were made in small containers with a flat surface of substrate at the bottom, we can exclude the role of target elevation in prey selection by tiger beetles as was suggested by Layne et al. (2006). Also, the role of the temperature, a factor noted as important in tiger beetles hunting in the wild (Dreisig, 1981), can be ignored as all the experiments were made under the same conditions.

Although tiger beetles can modify their diet according to types of prey which are actually available in the habitat (Sinu et al., 2006), the size of prey is the second important parameter playing a crucial role in hunting success of the predator (Alcock, 1993; Brose et al., 2006; Brose et al., 2008; Ball et al., 2015; Kalinkat et al., 2011). Generally it is known that at least in case of some predators, including different beetles (e.g. Vucic-Pestic et al., 2010; Kalinkat et al., 2011), the majority of predators actively prefer large prey, even if predator-prey body-size ratios vary across different habitats and predator and prey types and mean consumer-resource interaction strengths may be correlated with different habitat parameters and consumer types (Brose et al., 2006). Comparing with literature data we believe that also our results suggest that predator-prey body-size ratios can be important in case of both studied tiger beetle species (Fig.3). We have 
329 noted that Calomera littoralis preferred small prey with a small (caterpillars) and fast (ground 330 beetles) escape potential (51-100\% depending on the beetle's sex and type of prey), while the

331

332

333

334

335

336

337

338

339

340

341

342

343

344

345

346

347

348

349

350

351

352

353

354

355

356

357

358

359

medium-sized prey was chosen only in the case of slow moving caterpillars. A different situation was observed in the case of Cicindela hybrida. In this species, medium (43 or $66 \%$ depending on the beetle sex) and small-sized prey ( $43 \%$ in the case of females) was chosen only in the case of fast running ground beetles, while in the case of slow caterpillars much bigger individuals were attacked (47\% for both beetle sexes). The body length of both studied tiger beetle species is similar. On the other hand, $C$. hybrida has longer mandibles (up to $10 \%$ in females compared with Calomera littoralis; Jaskuła, 2005), the elements of mouthparts which play a key-role in catching and cutting the prey. Such a difference in the length of mandibles can explain the preference for bigger prey by Cicindela hybrida, especially in females, as it is known that longer mandibles allow them to keep a wider distance between the end parts of these organs when the mandibles are fully opened, and as a result potentially bigger prey can be caught (Pearson \& Mury, 1979). As mentioned above, hunting for bigger and easy to catch prey has great evolutionary sense from the predator's point of view, as such a strategy allows to keep energy for future activity of the predator (e.g. Brose et al., 2006; Brose et al., 2008; Ball et al., 2015; Kalinkat et al., 2011). This seems to be especially important in the case of females which need to accumulate much more energy for the breeding season than males (e.g.: for production of eggs and finding the right place to lay them) (Thornhill \& Alckock, 1983).

Both studied tiger beetle species located their prey visually and then tried to catch it after fast active pursuit interspersed by short stops. All these elements of hunting behaviour were earlier noted in C. hybrida (Świecimski, 1956) as well as in other tiger beetle species (e.g.: Gilbert, 1986; Gilbert, 1987; Gilbert, 1997) and seem to be very typical for all beetles classified in this group, even if at least some diurnal species can locate and catch prey without sight (Riggins \& Hoback, 2005). Although there are no data about the physiological base of such a pause-and-look behaviour in the case of the species studied by us, it is known that in other tiger beetles such a behaviour plays a very important role in the actualisation of prey position as the signal sent from ommatidia in the beetle's eyes to its central nervous system is slower that the speed of running tiger beetle (Gilbert, 1997). As in the cases of earlier studied tiger beetle species (e.g.: Świecimski, 1956; Pearson \& Knisley, 1985; Gilbert, 1987; Lovari et al., 1992; Gilbert, 1997; Zurek et al., 2014), we have noted that Calomera littoralis and Cicindela hybrida use mandibles 
360 to test the size, shape, and probably also noxious chemicals of their prey before it is killed and

361 eaten. The significant difference in the "testing behaviour" observed by us between both species 362 (releasing of prey in 58\% cases in Calomera littoralis and 78\% in Cicindela hybrida) is most 363 probably connected with the size of their preferred prey. Smaller prey can be faster and more 364 easily tested that the bigger one, and as a consequence can be killed quicker. Exactly such an 365 observation was noted in the case of Calomera littoralis which preferred smaller types of prey. On the other hand, Cicindela hybrida, which hunted mainly medium and/or larger prey, was characterised by a much longer "testing behaviour" (prey released in $75-76 \%$ of cases after the first attack). Such a behaviour seems to play an important role as the final hunting success was very similar in both species. Both tiger beetles clearly preferred attacking in the middle (the connection between the thorax and the abdomen in ground beetles) or in the middle or front part of the prey (the head or the thorax in caterpillars), almost ignoring the back parts. The explanation of such a hunting strategy is rather simple as the main muscles responsible for walking are places in the insect's thorax. Moreover, in the front part of the insect body (the head and partly the thorax), the main part of the insect nervous system in placed (Gilliot, 2005). As a consequence, an attack on these body parts usually allows to immobilise and kill the prey quickly. Although there is only a small number of studies on the hunting behaviour of tiger beetles, and therefore we cannot provide similar results from the literature, single field observations of the second author upon some European (Cephalota chiloleuca, C. circumdata, Cicindela campestris, C. sylvatica, Cylindera germanica, C. trisignata, Myriochila melancholica) and North African species (Grammognatha euphratica, Lophyra flexuosa) suggest that this is a common strategy among tiger beetles. Moreover, the same or very similar strategy can be found in other predatory insects which need to catch prey quickly, such as some diurnal ground beetles (e.g.: Bauer, 1981; Bauer 1985) as well as other terrestrial arthropods, including jumping spiders (e.g.: Jackson \& Pollard, 1996; Bartos, 2002; Bartos, 2007; Bartos, 2008; Bartos \& Minias, 2016).

\section{Conclusions}

The results of the presented study clearly confirm that the hunting behaviour of tiger beetles is complicated and multi-staged. Calomera littoralis and Cicindela hybrida are able to discriminate between different types of prey (both according to their size and escape potential) and apply 
391 different behavioural tactics to hunt them, what most probably is connected with predator-prey

392 body-ratio. Particular strategies are used to increase hunting success and as a result allow to 393 accumulate energy for future activity of the predator. Although there is a lack of similar data for

394 most of other tiger beetle genera, we should expect that this type of behaviour, very logical in the 395 wide evolutionary sense, is characteristic of the entire group. On the other hand, future studies, 396 especially on nocturnal and/or arboreal tiger beetle species which occupy different types of 397 environment or hunt at night, may provide additional facts about hunting strategies of 398 Cicindelidae.

399

400

401

402

403

404

405

406

407

408

409

410 Bartos M, Minias P. 2016. Visual cues used in directing predatory strikes by the jumping spider 411 Yllenus arenarius (Araneae, Salticidae). Animal Behaviour 120: 51-59.

\section{Literature:}

Alcock J. 1993. Animal behavior: an evolutionary approach. Sinauer Associates, Sunderland. Ball SL, Woodcock BA, Potts SG, Heard MS. 2015. Size matters: body size determines functional responses of ground beetle interactions. Basic and Applied Ecology 16: 621-628. Bartos M. 2002. Distance of approach to prey is adjusted to the prey's ability to escape in Yllenus arenarius Menge (Araneae, Salticidae). European Arachnology 2000: 33-38.

Bartos M. 2007. Hunting prey with different escape potentials - alternative predatory tactics in a dune dwelling salticid. The Journal of Arachnology 35: 499-508.

Bartos M. 2008. Alternative predatory tactics in a juvenile jumping spider. The Journal of Arachnology 36: 300-305.

412 Bauer T. 1981. Prey capture and structure of the visual space of an insect that hunts by sight on 413 the litter layer (Notiophilus biguttatus F., Carabidae, Coleoptera). Behavioral Ecology and 414 Sociobiology 8: 91-97.

415 Bauer T. 1985. Different adaptation to visual hunting in three ground beetle species of the same 416 genus. Journal of Insect Physiology 31 (8): 593-601.

417 Bonsall MB, Hassell MP. 2007. Predator-prey interactions. pp. 46-61. In: May R, McLean A 418 (eds) Theoretical Ecology: Principals and Applications. Oxford: Oxford University Press.

419 Creel S, Christianson D. 2008. Relationships between direct predation and risk effects. Trends in 420 Ecology \& Evolution 23: 194-201. 
421 Brose U, Ehnes RB, Rall BC, Vucic-Pestic O, Berlow EL, Scheu S. 2008. Foraging theory

422 predicts predator-prey energy fluxes. Journal of Animal Ecology 77: 1072-1078.

423 Brose U, Jonsson T, Berlow EL, Warren P, Banasek-Richter C, Bersier L-F, Blanchard JL, Brey

424 T, Carpenter SR, Blandernier M-FC, Cushing L, Dawah HA, Dell T, Edwards F, Harper-Smith

425 S, Jacob U, E. Ledger ME, Martinez ND, Memmott J, KATJA Mintenbeck K, Pinnegar JK, Rall

426 BC, Rayner TS, Reuman DC, Ruess L, Ulrich W, Williams RJ, Woodward G, Cohen JE. 2006.

427 Consumer-resource body-size relationships in natural food webs. Ecology 87 (10): 2411-2417.

428 Curio E. 1976. Ethology of predation. Springer-Verlag. Berlin, 250pp.

429 Dreisig H. 1981. The rate of predation and its temperature dependence in a tiger beetle,

430 Cicindela hybrida. Oikos 36: 196-202.

431 Gilbert C. 1986. A morphological and cinematographic analysis of tiger beetle predatory

432 behaviour (Carabidae: Cicindelinae). 43-57 pp. In: den Boer PJ, Mossakowski D, Luff ML,

433 Weber F. (eds) Carabid beetles, Their adaptations and dynamics. Gustav-Fisher, Stuttgart.

434 Gilbert C. 1987. Visual control of prey pursuit by tiger beetles. In: Hamdorf K (ed.) Insect

435 Vision. Hamburg, Germany.

436 Gilbert C. 1997. Visual control of cursorial prey pursuit by tiger beetles (Cicindelidae). Journal

437 of Comparative Physiology a-Sensory Neural and Behavioral Physiology181(3): 217-230.

438 Gilliot C. 2005. Entomology. Third Edition. Springer

439 Hill JM, Knisley CB. 1992. Frugivory in the tiger beetle, Cicindela repanda (Coleoptera:

440 Cicindelidae). The Coleopterologists Bulletin 46(3): 306-310.

441 Hori M. 1982. The biology and population dynamics of the tiger beetle Cicindela japonica

442 (Thunberg). Physiology and Ecology Japan 19: 177-212.

443 Jackson RR, Pollard SD. 1996. Predatory behavior of jumping spiders. Annual Review of

444 Entomology 41: 287-308.

445 Jaskuła R. 2005. Mandible sexual dimorphism in Cicindela hybrida hybrida (Cicindelidae). 233-

446 239pp. In: Skłodowski J, Huruk S, Barševskis A, Tarasiuk S (eds.) Protection of Coleoptera in

447 the Baltic Sea Region. Warsaw Agricultural University Press. Warsaw. 239pp.

448 Jaskuła R. 2011. How unique is the tiger beetle fauna (Coleoptera. Cicindelidae) of the Balkan

449 Peninsula? ZooKeys 100: 487-502. 
450 Jaskuła R. 2013. Unexpected vegetarian feeding behaviour of a predatory tiger beetle Calomera 451 littoralis nemoralis (Olivier, 1790) (Coleoptera: Cicindelidae). Journal of the Entomological 452 Research Society 15(1): 1-6.

453 Jaskuła R. 2015. The Maghreb - one more important biodiversity hot spot for tiger beetle fauna 454 in the Mediterranean region. ZooKeys 482: 35-53.

455 Jaskuła R., Rewicz T. 2015. Tiger beetles (Coleoptera: Carabidae: Cicindelinae) of Tunisia: 456 distribution, phenology, taxa list and new records. African Entomology 23(2): 467-485.

457 Jaskuła R, Rewicz T, Kwiatkowski K. 2015. Tiger beetle fauna (Coleoptera: Carabidae, 458 Cicindelinae) of Morocco: distribution, phenology and list of taxa. Entomologica Fennica 26: 459 132-155.

460 Jaskuła R, Rewicz T, Płóciennik M, Grabowski M. 2016. Pleistocene phylogeography and 461 cryptic diversity of a tiger beetle, Calomera littoralis, in North-Eastern Mediterranean and Pontic 462 regions inferred from mitochondrial COI gene sequences. PeerJ 4: e2128; DOI 46310.7717 peerj. 2128

464 Kalinkat G, Rall BC, Vucic-Pestic O, Brose U. 2011. The Allometry of Prey Preferences. PLoS 465 ONE 6(10): e25937.

466 Kaulbars MM, Freitag R. 1993. Foraging behaviour of the tiger beetle Cicindela denikei Brown 467 (Coleoptera: Cicindelidae). Canadian Field-Naturalist 107: 53-58.

468 Larochelle A. 1974. The food of Cicindelidae of the world. Cicindela 6: 21-43.

469 Layne JE, Chen PW, Gilbert C. 2006. The role of target elevation in prey selection by tiger

470 beetles (Carabidae: Cicindela spp.). Journal of Experimental Biology 209(21): 4295-4303.

471 Lovari S, Favilli L, Eusebi MP, Cassola F. 1992. The effects of prey movement, size and colour

472 in the attack/avoidance behaviour of the tiger beetle Cephalota circumdata leonschaeferi

473 (Cassola) (Coleoptera, Cicindelidae). Ethology, Ecology and Evolution, 4: 321-331.

474 Moore BP. 1979. Chemical defence in carabids and its bearing on phylogeny. 193-204pp. In:

475 Erwin TL, Ball GB, Whitehead DR (eds) Carabid beetles: their revolution, natural history, and 476 classification. Proceedings of the First Symposium of Carabidology, Smithonian Institution, 477 Washington, D. C.

478 Pearson DL. 1988. Biology of Tiger Beetles. Annual Review of Entomology33: 123-147.

479 Pearson DL, Mury EJ. 1979. Character divergence and convergence among tiger beetles 480 (Coleoptera: Cicindelidae). Ecology 60 (3): 557-566. 
481 Pearson DL, Knisley CB. 1985. Evidence for food as a limiting resource in the life cycle of tiger 482 beetles (Coleoptera: Cicindelidae). Oikos 45: 161-168.

483 Pearson DL, Vogler AP. 2001.Tiger beetles: the evolution, ecology and diversity of the 484 cicindelids. Cornell University Press. Ithaca/London. 333pp.

485 Riggins JJ, Hoback WW. 2005. Diurnal tiger beetles (Coleoptera: Cicindelidae) capture prey 486 without sight. Journal of Insect Behaviour 18(3): 305-312.

487 Sinu PA, Nasser M, Rajan PD. 2006. Feeding fauna and foraging habits of tiger beetles found in 488 agro-ecosystems in Western Ghats, India. Biotropica 38 (4): 500-507.

489 Świecimski J. 1956. The role of sight and memory in food capture by predatory beetles of the 490 species Cicindela hybrida L. (Coleoptera, Cicindelidae). Polskie Pismo Entomologiczne, 26 (15): $491 \quad 205-232$.

492 Thornhill R, Alckock J. 1983. The evolution of insect mating systems. Harvard University Press. 493 Cambridge/London. 546pp.Vucic-Pestic O, Rall BC, Kalinkat G, Brose U. 2010. Allometric 494 functional response model: body masses constrain interaction strengths. Journal of Animal 495 Ecology 79: 249-256.

496 Wiesner J. 1992. Verzeichnis der Sandlaufkäfer der Welt-Checklist of the Tiger Beetles of the 497 World. Verlag Erna Bauer, Keltern, Germany.

498 Zurek DB, Perkins MQ, Gilbert C. 2014. Dynamic visual cues induce jaw opening and closing 499 by tiger beetles during pursuit of prey. Biology Letters 10: 20140760. 
Figure 1

Number of chosen preys by male and females of Calomera littoralis and Cicindela hybrida respectively in experiment 1.

Colors of vertical bars are showing respectively: grasshopper - grey, caterpillar - white, beetle - black.

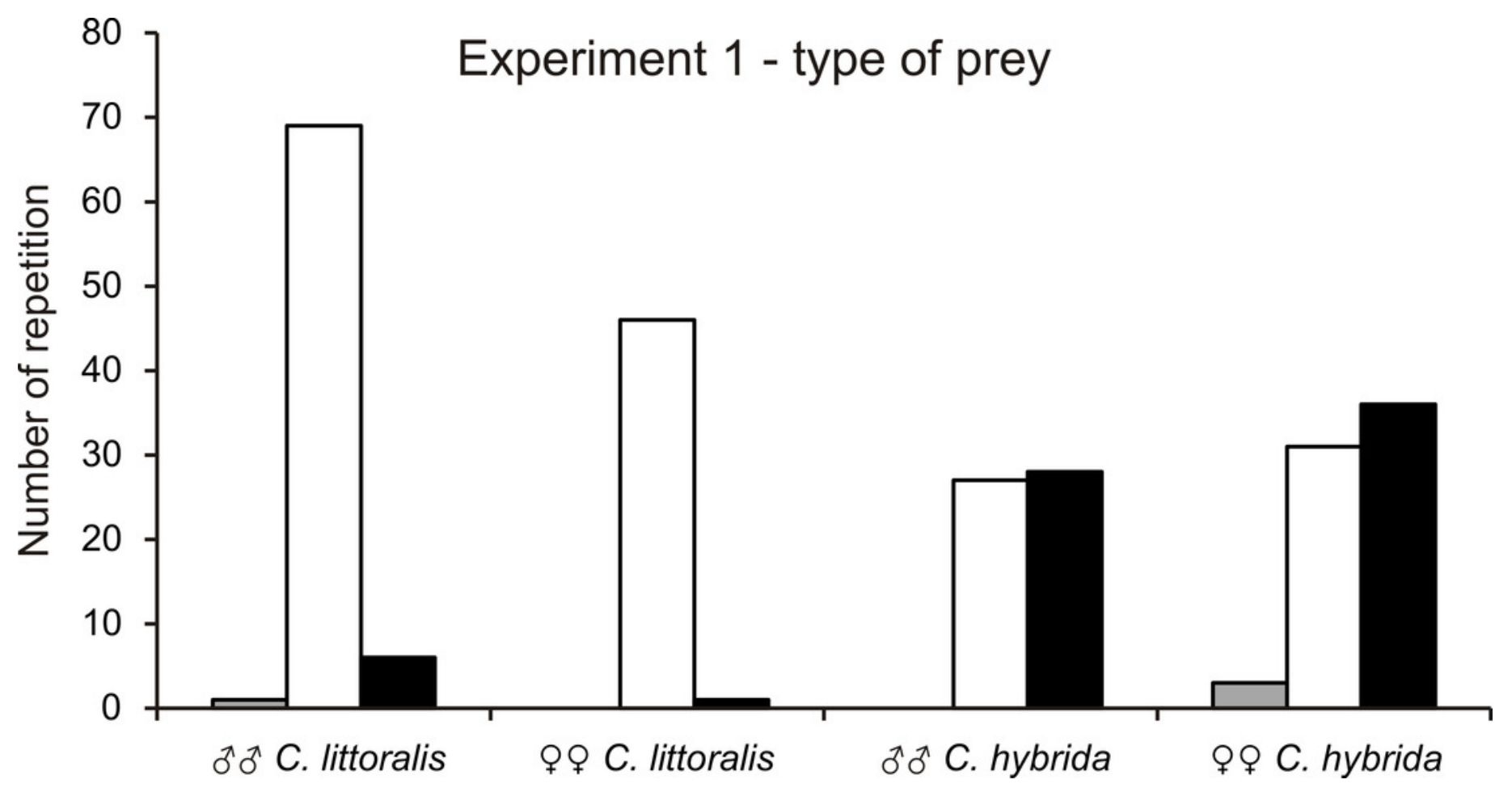


Figure 2

Number of chosen preys by males and females of Calomera littoralis and Cicindela hybrida in experiment 2 for beetles and caterpillars in part A and B respectively.

In both cases colors correspond to size of the prey in the following pattern: grey - small, white - medium, black - large. 

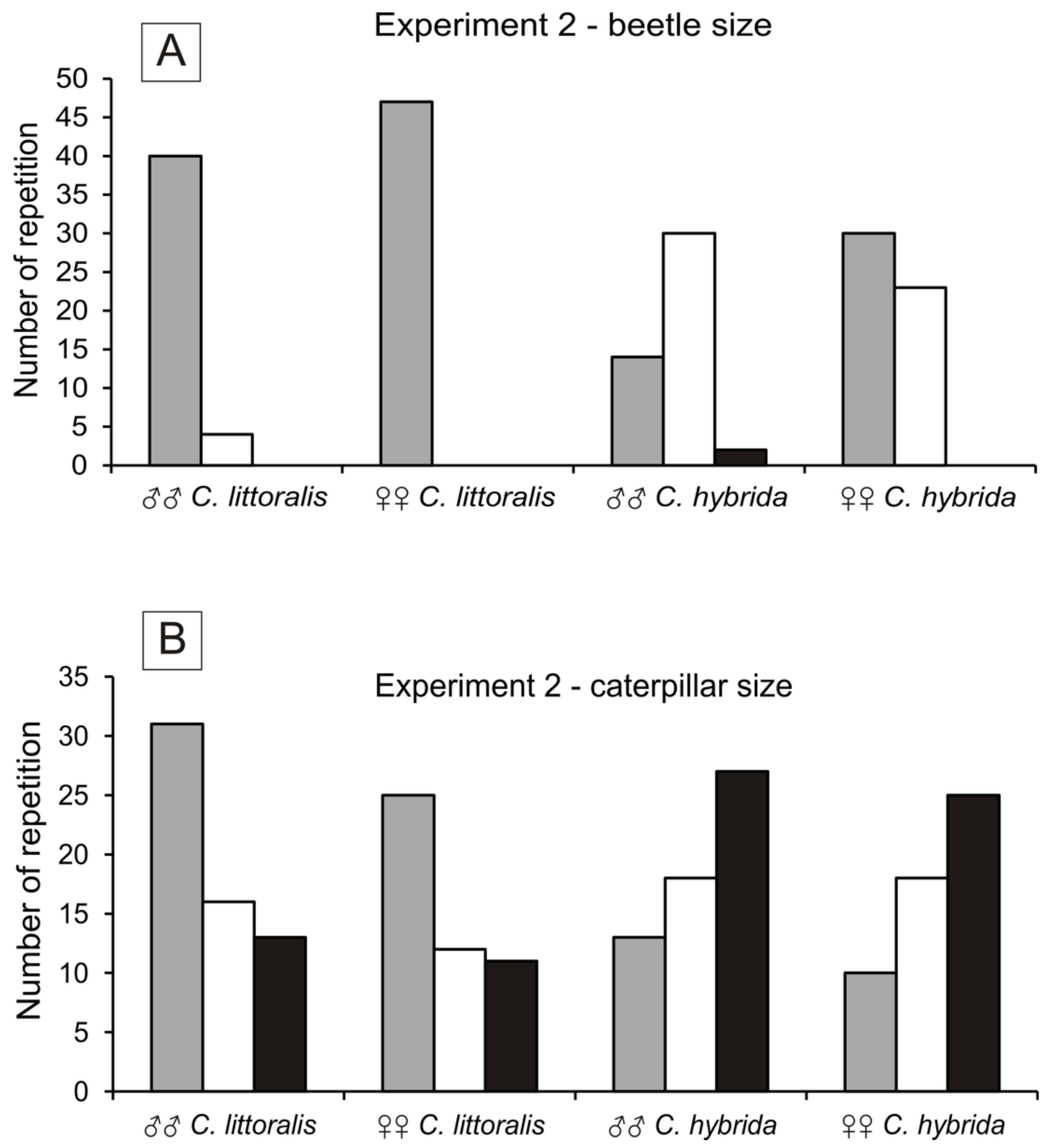
Figure 3

Plot of predator-prey body-size ratios: A - Cicindela hybrida vs. beetles, B - C. hybrida vs. caterpillars, C - Calomera littoralis vs. beetles, D - C. littoralis vs. caterpillars.

In all cases blue diamonds and dashed line correspond to males and red circles and solid line to females.
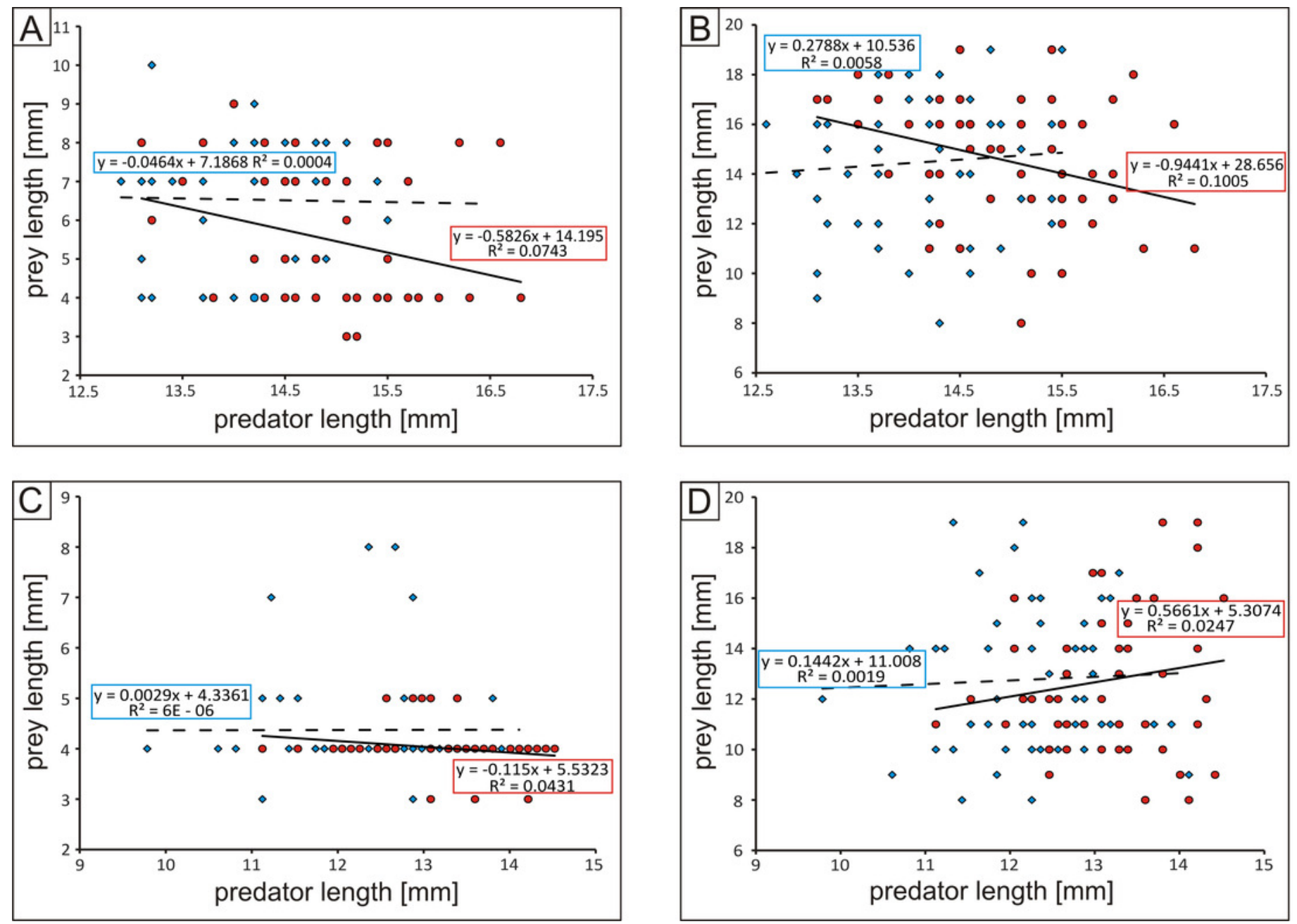


\section{Figure 4}

The flow diagrams of Calomera littoralis hunting small caterpillar (A), small beetle (C); and Cicindela hybrida hunting large caterpillar (B), and medium beetle (D).

The frequency of particular steps of the hunting strategy was calculated as a percentage of such behaviour in relation to all possible behaviours between two successive stages of hunting, and was indicated by the appropriate line width in the diagram and by the number below the repetition number of such behaviour. The sequence should be read from left to right unless indicated by an arrow. 
A Calomera littoralis small caterpillar

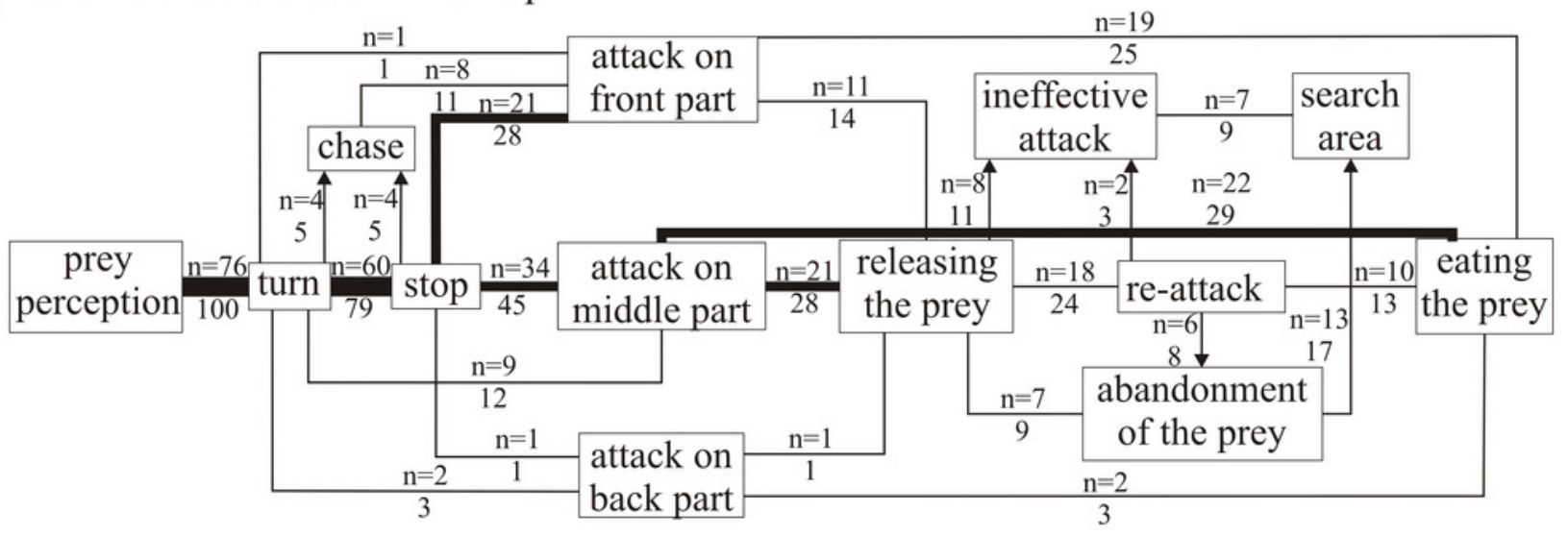

B Cicindela hybrida large caterpillar

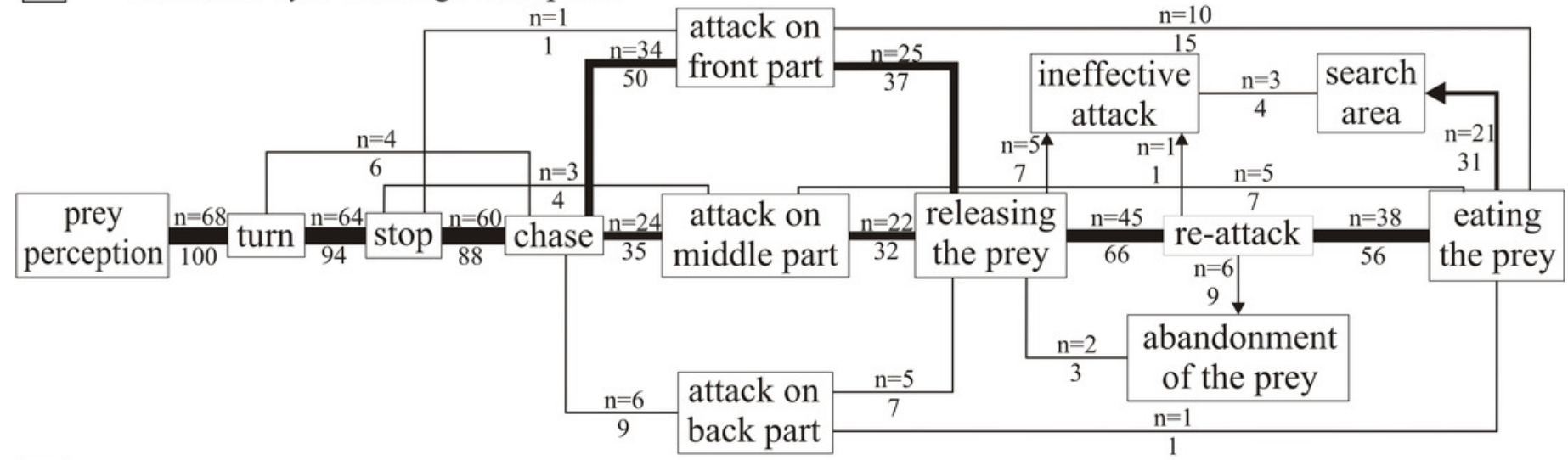

C Calomera littoralis small beetle

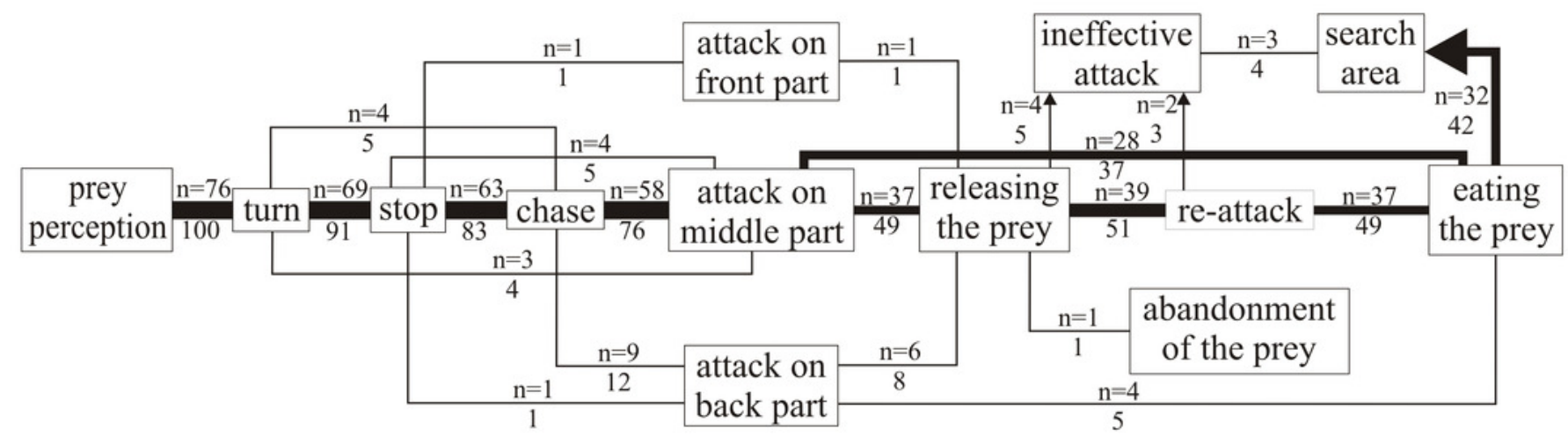

D Cicindela hybrida medium beetle

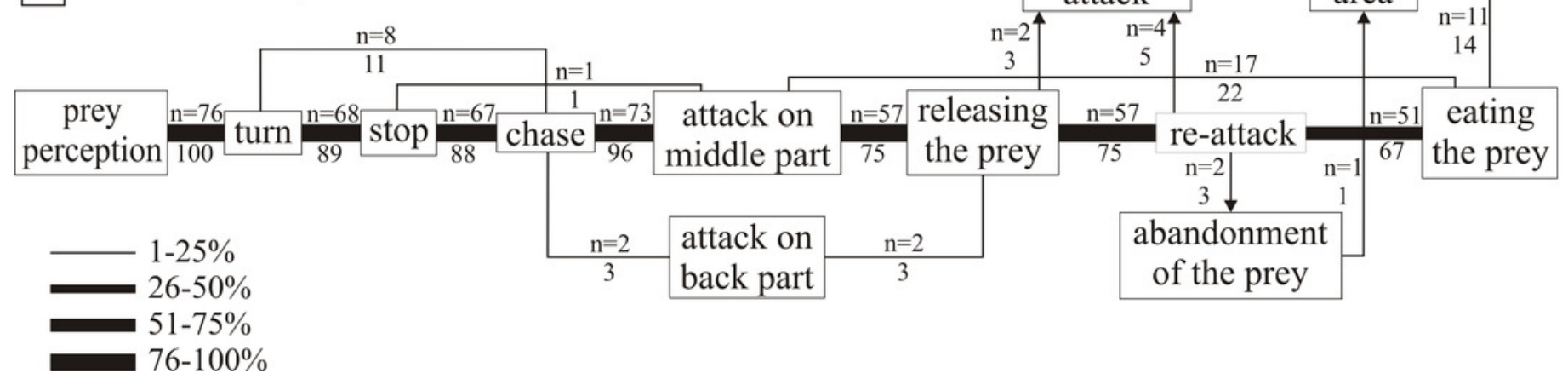




\section{Table $\mathbf{1}$ (on next page)}

Prey taxa used in the experiments. 


\begin{tabular}{|l|l|l|l|c|c|c|c|}
\hline Prey species & Order/Family & $\begin{array}{l}\text { Size } \\
\text { type }\end{array}$ & $\begin{array}{l}\text { Ability } \\
\text { to escape }\end{array}$ & $\begin{array}{l}\text { Length } \\
(\mathrm{mm})\end{array}$ & Mean & Weight (g) & Mean \\
\hline grasshopper & Orthoptera & - & high & - & - & - & - \\
\hline $\begin{array}{l}\text { Metalina } \\
\text { lampros/properans }\end{array}$ & Carabidae & small & medium & $3-5$ & $\begin{array}{l}4.0 \\
\pm 0.44\end{array}$ & $2-5$ & $\begin{array}{c}3.8 \\
\pm 0.88\end{array}$ \\
\hline $\begin{array}{l}\text { Calathus } \\
\text { melanocephalus }\end{array}$ & Carabidae & medium & medium & $6-9$ & 7.5 & $8-28$ & 16.5 \\
& & & & & \pm 0.68 & & \pm 4.12 \\
\hline C. fuscipes & Carabidae & large & medium & $9-11$ & 9.9 & $36-68$ & 49.4 \\
& & & & & \pm 0.55 & & \pm 7.46 \\
\hline Symphyta & Hymenoptera & small & low & $8-12$ & 10.4 & $17-40$ & 28.2 \\
& & & & \pm 1.13 & & \pm 4.27 \\
\hline Symphyta & Hymenoptera & medium & low & $12-15$ & 13.8 & $32-63$ & 46.4 \\
& & & & \pm 0.81 & & \pm 8.62 \\
\hline Symphyta & Hymenoptera & large & low & $15-21$ & 17.3 & $55-97$ & 77.0 \\
& & & & \pm 1.25 & & \pm 11.9 \\
\hline
\end{tabular}

1

2 


\section{Table 2 (on next page)}

Number of repetitions, and types of the prey in each experiment.

* abbreviations: $\mathrm{N}$ - number of repetition, gra - grasshopper, $\mathrm{s}$ bet - small beetle, $\mathrm{m}$ bet medium beetle, I bet - large beetle, s cat - small caterpillar, $\mathrm{m}$ cat - medium caterpillar, I cat large caterpillar. 


\begin{tabular}{|c|c|c|c|c|c|c|c|c|c|c|}
\hline \multirow[t]{3}{*}{ Species } & \multirow{2}{*}{\multicolumn{2}{|c|}{ experiment 1}} & \multicolumn{4}{|c|}{ experiment 2} & \multicolumn{4}{|c|}{ experiment 3} \\
\hline & & & \multicolumn{2}{|c|}{ caterpillar } & \multicolumn{2}{|r|}{ beetle } & \multicolumn{2}{|c|}{ caterpillar } & \multicolumn{2}{|c|}{ beetle } \\
\hline & $\mathrm{N}$ & type & $\mathrm{N}$ & size & $\mathrm{N}$ & size & $\mathrm{N}$ & size & $\mathrm{N}$ & size \\
\hline 우 Calomera littoralis & 47 & $\begin{array}{l}\text { gra, } \\
\text { m bet, } \\
\text { m cat }\end{array}$ & 48 & $\begin{array}{l}\text { s cat, } \\
\text { m cat, } \\
1 \text { cat }\end{array}$ & 47 & $\begin{array}{l}\text { s bet, } \\
\text { m bet, } \\
1 \text { bet }\end{array}$ & 38 & s cat & 38 & s bet \\
\hline ô Calomera littoralis & 76 & $\begin{array}{c}\text { gra, } \\
\text { m bet, } \mathrm{m} \text { cat }\end{array}$ & 60 & $\begin{array}{c}\mathrm{s} \text { cat, } \\
\mathrm{m} \text { cat, } 1 \text { cat }\end{array}$ & 44 & $\begin{array}{l}\mathrm{s} \text { bet, } \\
\mathrm{m} \text { bet, } \\
1 \text { bet }\end{array}$ & 38 & s cat & 38 & $\mathrm{~s}$ bet \\
\hline 우우 Cicindela hybrida & 70 & $\begin{array}{l}\text { gra, } \\
\text { m bet, } \\
\text { m cat }\end{array}$ & 53 & $\begin{array}{l}\mathrm{s} \text { cat, } \\
\mathrm{m} \text { cat, } \\
1 \text { cat }\end{array}$ & 53 & $\begin{array}{l}\mathrm{s} \text { bet, } \\
\mathrm{m} \text { bet, } \\
\mathrm{l} \text { bet }\end{array}$ & 32 & 1 cat & 38 & $\mathrm{~m}$ bet \\
\hline ồ Cicindela hybrida & 55 & $\begin{array}{c}\text { gra, } \\
\text { m bet, } \mathrm{m} \text { cat }\end{array}$ & 58 & $\begin{array}{c}\text { s cat, } \\
\mathrm{m} \text { cat, } 1 \text { cat }\end{array}$ & 46 & $\begin{array}{c}\mathrm{s} \text { bet, } \\
\mathrm{m} \text { bet, } 1 \text { bet }\end{array}$ & 36 & 1 cat & 38 & $\mathrm{~m}$ bet \\
\hline
\end{tabular}

1 